\title{
The Continuation of Local Landscape in Modern Design
}

\author{
Chen Huanhuan \\ Jishou University, Hunan, China \\ Email: 546690459@qq.com
}

\begin{abstract}
With the advent of the global cultural crisis, local culture has attractedl more and more attention from the public. The flow of new landscape works emerging in the urban construction may bring us surprise for an instant, but human beings will also find there are so many regrets and problems left behind, especially, the various cities with homogeneous landscape, various places of interest with homogeneous scenery and the costly "exotic flowers" and "exotic plants". The lack of local geographical features and culture has become a common problem in the landscape works of urban construction in many cities. The reason is found to be the fact that people intend to ignore the role of native culture in landscape design, and additionally overlook the integration of local culture into the design while drawing more lessons from the foreign experience.

The elements of the vernacular landscape come from rural life and also nature, which is simple and unpretentious, full of regional characteristics. And there are significant differences between different regions. For example, the quadrangle dwellings in Beijing, the caves in northern Shaanxi, and the towers in the south of China are the vernacular landscapes in different regions. The author finds that the elements of ordinary and natural vernacular landscape can be expressed in a reasionable way so as to maximize the presentation of characteristics of the vernacular landscape and to form a landscape full of regional culture.
\end{abstract}

Keywords: Local landscape; history; cultural continuity

\section{Introduction}

The vernacular landscape can be considered as a kind of visible human history. With the rapid development of urbanization, it can be easily found that the local culture, local ecology, and local style and features are gradually disappearing from modern design. In order to realize extraordinary application of the vernacular landscape in modern design, a few problems must be solved (Fig.1).
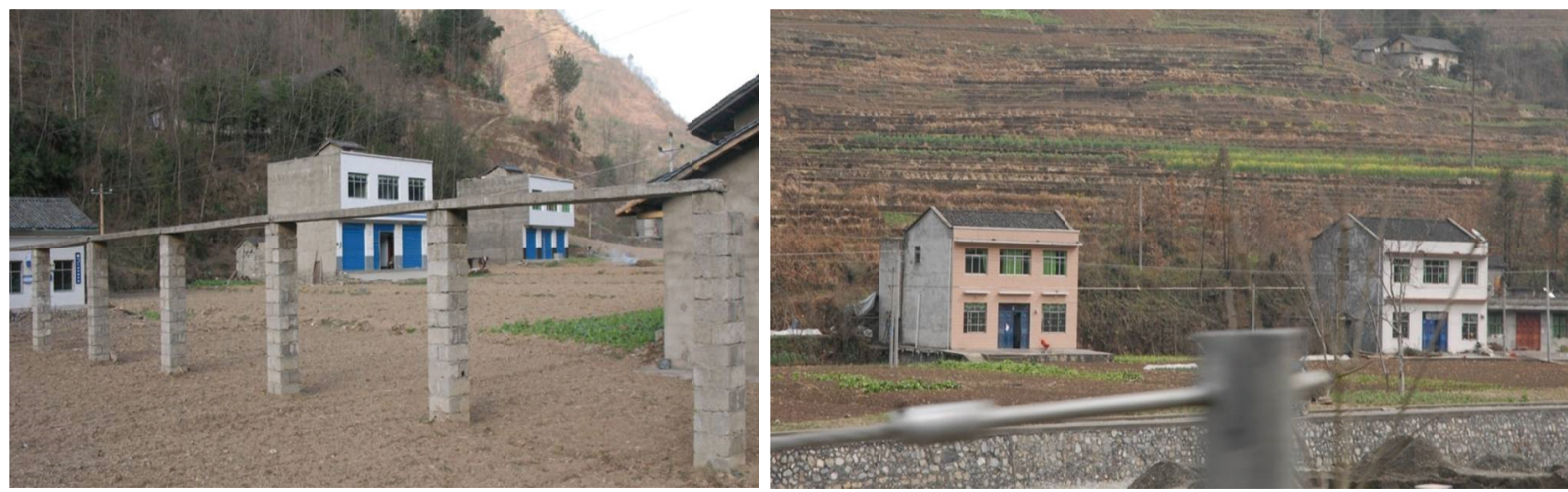

Figure 1. New countryside

\subsection{The Oblivion of Local Material}

The local materials have adapted to the terrain, climate and soil in the specific region. They are cheap and capable of being obtained locally (Fig.2). Compared with some other expensive materials that are 
not suitable for being planted in the specific region, the local materials can not only satisfy economic benefits but also achieve the sustainable development as well as protection for the natural environment. The local materials are mainly natural physical elements such as local buildings, artifacts, and local vegetation. There is a close connection between the local materials and the environment, which is the product of experience generated by repeated adaptations in the past thousands of years.
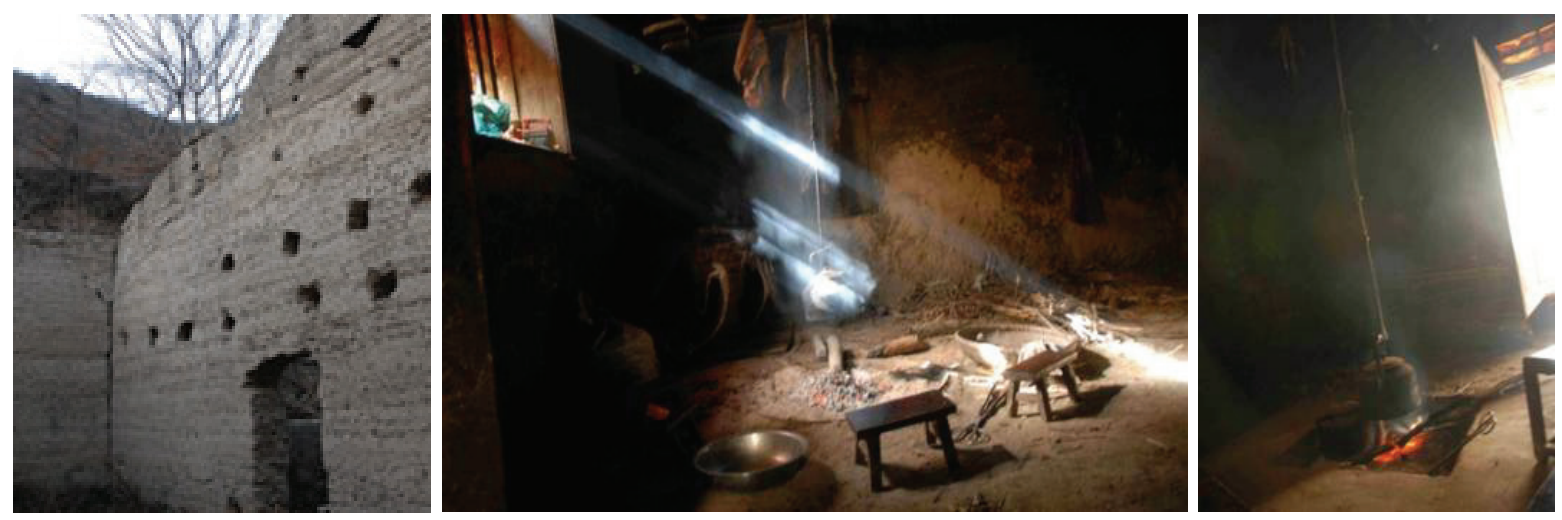

Figure 2. An abandoned farmhouse

\subsection{Lack of Local Culture}

The local culture is the local spirit, the local complex, the local artistic conception contained in the local landscape. Local culture is the essence of landscape expression, which is precipitated in the development of regional history and is usually manifested as immaterial form. It is the unique custom and custom of people living in the environment, and it is the experience and summary of people's life. It mainly refers to some unique dialects, dress, dance and festivals, but also some code words, taboos, secrets. They are the essence of the local landscape is gradually precipitated in the process of historical development [1]. The lack of due attention in modern design makes its living space smaller and smaller until it disappears.

\subsection{The Loss of a Vernacular Style}

The local landscape is the natural landscape of the countryside, including geology, geomorphology, climate, hydrology and other factors. The local style can arouse people's rural feelings and recall the local people nostalgic natural scenery.

In modern landscape design, landscape designers often ignore the survey of the existing local features, which not only causes a loss of local features, but also causes serious damages to the natural environment. Local features of construction and local stories represent the combination of construction and rural atmosphere, which stimulates people's nostalgia.

\section{Goals and Principles}

\subsection{The Ancient Town}

The concentration and crystallization of the characteristics of local culture is very important. Ensuring the authenticity of the vernacular landscape largely determines the value of the vernacular landscape, especially its historical value. Therefore, the protection for authenticity in the local place should be aimed at all historical information. The protection for all historical information is required not only to respect the long-standing tangible and intangible heritage, but also to respect the additional parts and modified parts of information in subsequent times, so that the detailed history is clear and readable for the present and future generations. 


\subsection{The Relationship Between "History" and "Modern Times"}

On one hand, judging from the static point of view, "history" does not include "modern times", and there is obvious time boundary between the two ages. On the other hand, from a dynamic point of view, the "modern times" will eventually be added to history and become a part of "history" [2]. The current vernacular landscape records the information that occurs in real life while recording information in historical life. In the design, in case of the excessive emphasis on history, the blind and stubborn imitation of ancient style, and ignorance of the information of the real life, the designer will fail to record the authentic information. In this way, the authenticity of the vernacular landscape will be destructed.

Therefore, only the maximum preservation of the collective historical information of the vernacular landscape can protect the historical value of the landscape. The protection for authenticity of the ancient town aims to allow people to understand and remember the past, also know and cherish the present.

\subsection{Change the Basic Starting Point of Design to A Considerable Extent}

Considering from the historical perspective can make up for the weakness of the design to a certain extent, and teach us what kind of spatial form is more suitable for the local place. Because of the limitation of standpoint and visual angle, people unconsciously magnify the part of design creation, and to a certain extent change the basic starting point of design. If we can take a historical perspective, this partly makes up for the weakness of the design and tells us what spatial form is more appropriate for the local.

\section{Methods}

\subsection{Direct Application of Local Artifacts}

The local artifacts mainly refer to the items that originally served us in the lives, such as crafts, water tanks, pig troughs, graphite and others. After being processed simply, the artifacts can immediately have new meanings in our modern design [3]. The new meanings are given to the traditional materials by means of creative landscaping. The local materials have the advantages of easy material collection and money saving. Moreover, the use of materials from different regions can also highlight the uniqueness of the landscape. The ordinary materials can become uncommon after being processed.

On one hand, these materials with original life functions applied to landscaping are highly regional and iconic. On the other hand, there will be a strong contrast between local artifacts and modern landscape design so as to achieve expected artistic effect. For example, we can decorate the stone walls with the local artifacts. These artifacts carrying our historical memories should not disappear, and will become the landscape elements when they are inlaid in stone walls. For another example, the pig trough nowadays is no longer used to store the forage, but used as a flower pot filled with flowers on the stone wall. When these local artifacts are qualified with new functions, there are the motivation and reason for their continuation. Processing and utilization of local materials.

\subsection{Processing and Utilization of Local Materials}

The local materials mainly include the natural materials in the local place, such as plants, bricks, stone and others. The new meanings are given to the traditional materials by means of creative landscaping. The local materials have the advantages of easy material collection and money saving. Moreover, the use of materials from different regions can also highlight the uniqueness of the landscape. The ordinary materials can become uncommon after being processed.

For example, using local stone as the material to build the landscape wall can not only bring a simple, heavy feeling, but also coordinate with the surrounding environment (Fig.3). In the process of construction, we integrated the local residents. What we need is not a neat and uniform wall, but the simple material beauty created by people in the process of labor. 
The construction mode and technology of rammed earth dwellings are studied and improved to solve the new requirements of indoor living on the basis of preserving traditional technologies. This architectural strategy is the internal driving force to retain regional culture, inherit traditional technologies and promote sustainable development.

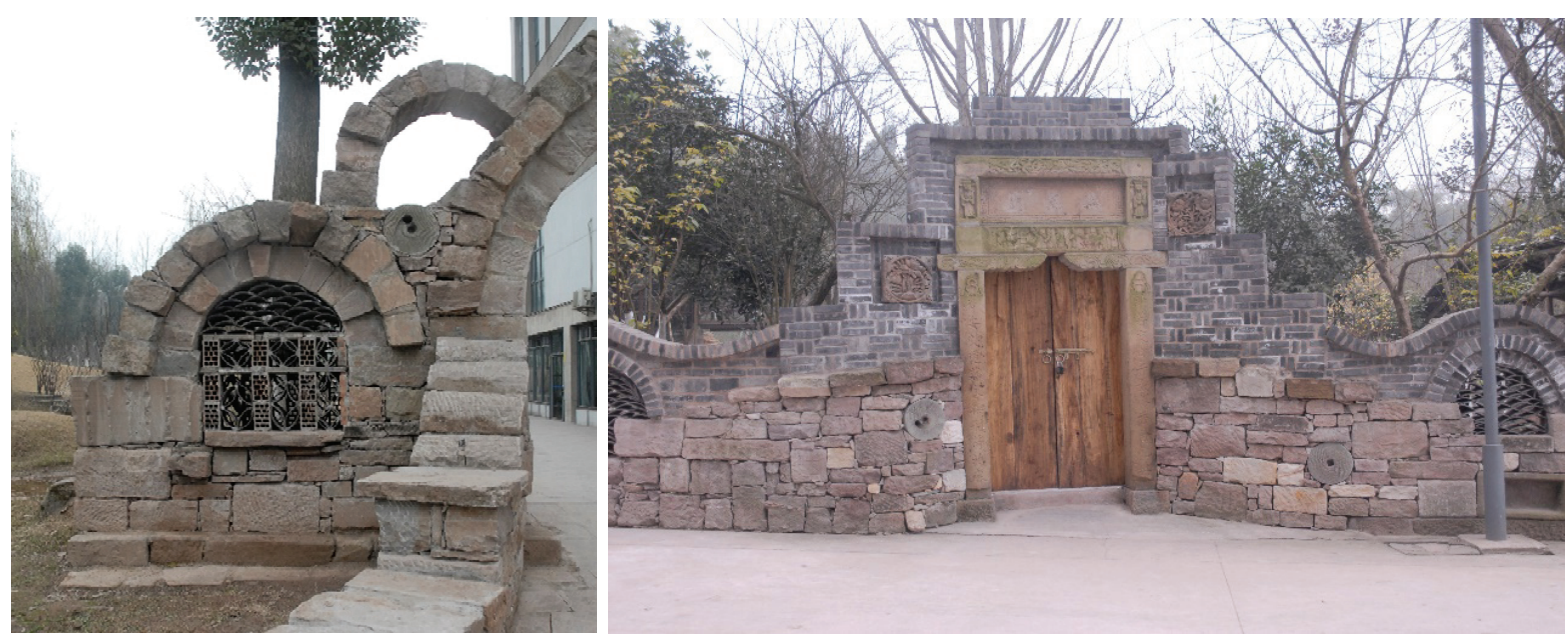

Figure 3. Stone wall

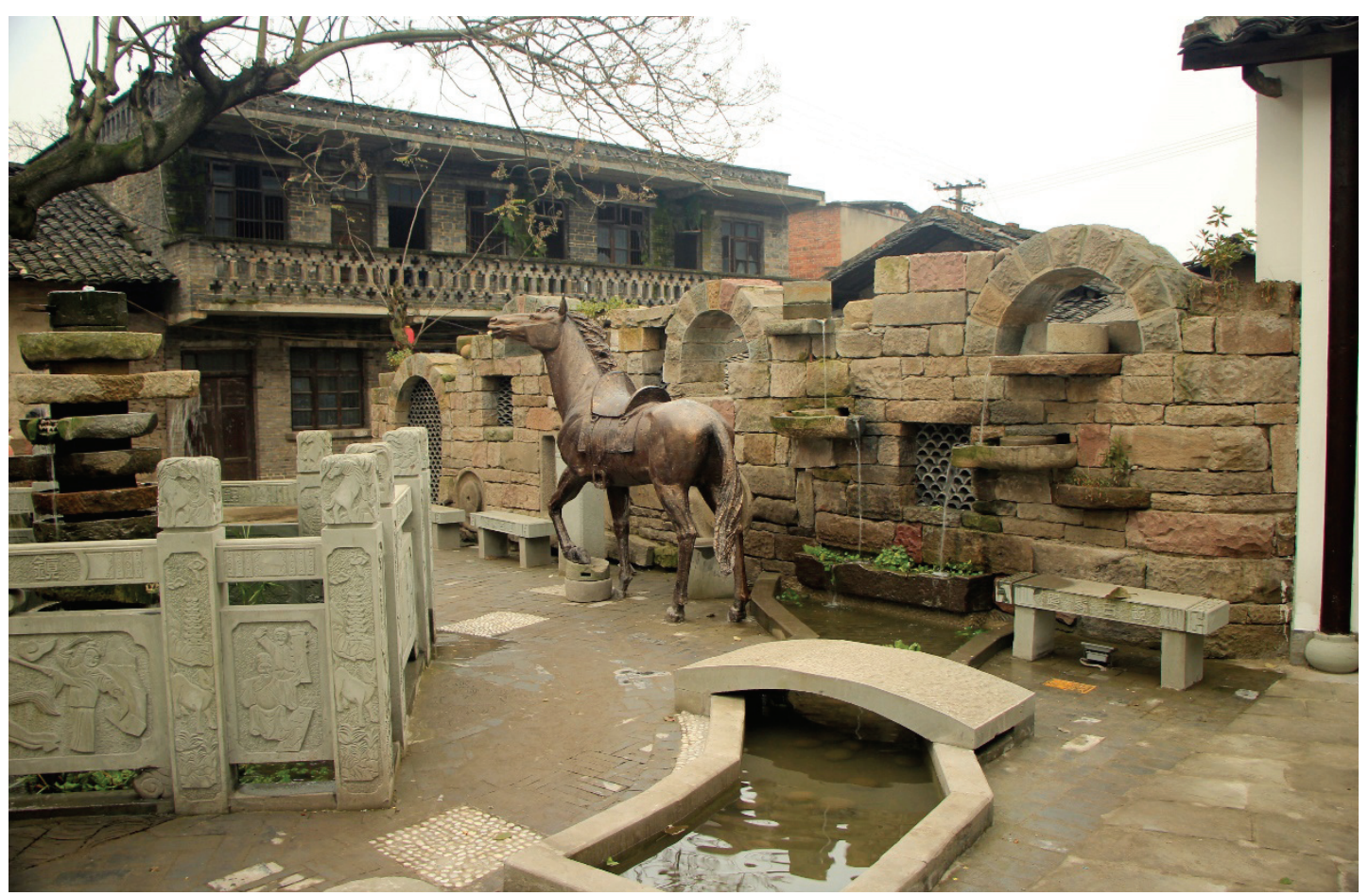

Figure 4. Recovery of life scenarios

\subsection{Local Scene Reappearance}

Many of the local stories still exist in an intangible form, requiring to be processed in artistic ways. Through the generalization of the local stories, the reconstruction of the scenes can be realized. The local scenes include custom activities, important historical events and historical remains. When the story 
is presented in a specific scene, the strong feeling of homesickness can also be common to the audience. Such a presentation makes the audience understand the cultural background of different regional lives and strikes a chord among everyone. For instance, the scenes in tea house are reconstructed in the form of short act and become tangible through the secondary art processing, forming a memory of the state of the past life (Fig.4).

\section{Summary}

In summary, this paper explores the methods of application of vernacular landscape in modern design along with the classification of three design methods, and expounds the considerations on how to continue the presentation of vernacular landscape in modern design, so that there is the foundation for the existence and development of the vernacular landscape. It is hoped that the vernacular landscape will be neither the water without a source nor a tree without roots. There are several inspirations given to future design as follows. First, the continuity of the vernacular landscape is the root and source of its development in modern design. Second, the continuity of the vernacular landscape is the basis for the construction of a unique regional and cultural landscape. Third, the continuity of the vernacular landscape is the starting point and driving force of modern landscape creation. Therefore, in the process of rapid urbanization, how to realize the continuation of the vernacular landscape has attracted more and more attention. The continuation of the vernacular landscape not only creates a regional and cultural landscape and maintains regional characteristics in modern design, but also constantly shapes itself during the inheritance of history and culture.

\section{References}

1. Yu Kongjian, Wang Zhifang, Huang Guoping. On Local Landscape and its significance to Modern Landscape Design [J] Huazhong Architecture, 2005 (4); 123.

2. Bo Guixi. Local knowledge and its utilization and protection. Anthropology and Native China [M]. Harbin: Heilongjiang people's Press, 2006.

3. Chen Jing, Shan Deqi. Native avantgarde-the native settlement in the view of earth art [J]. Architect Wu Zhengguang. 